\title{
THE POST-CRITICAL FUTURE OF LEGAL THEORY
}

\author{
Mark V. Tushnet
}

I take the title of Post-Critical Legal Theory to mean Post-Critical Legal Studies. There are two things that I want to say about what the critical legal studies idea does to problems of jurisprudence. The first is that it is not clear to me that critical legal studies want to be characterized primarily as a form of jurisprudence. My own inclination is to stress the political orientation of post-critical legal studies and to say that things that are called critical legal studies are unified primarily by a certain kind of political project rather than by any unifying concept about the nature of law. Having said that, though, Critical Legal Studies is a more complicated phenomenon, which leads to my second point. It is a phenomenon that locates itself in law schools and for the political project to work in law schools, it is psychologically and, probably, institutionally necessary that there be not just a unifying political project but a sense that there is some common ground other than politics. It is a movement of legal thinkers about law and, therefore, they have to think about something rather than vote for the same people.

With that psychological background, it does seem to me that there are two points about critical legal studies that are widely shared. The first is the notion of indeterminacy. You can have a range of views on the degree of indeterminacy out there. What characterizes critical studies people is that we tend to think that there is a lot more indeterminacy than other people seem to think. I've invented a measure called the "determinile" that goes from zero to one hundred. We think that the legal system is located at five to fifteen, while more centrist scholars locate it at forty to sixty, so there is a large gap. Nobody in critical studies thinks it is zero and nobody in centrist jurisprudence thinks that it is one hundred. The second shared notion is a response to post-legal realist scholarship in the United States, which turned towards policy sciences or policy orientation to resolve whatever degree of indeterminacy people believe that there is. This second shared notion is that the recourse to policy orientation ultimately failed for a variety of. reasons. One was the intractability of the social world, such that the policy could not really tell you anything interesting about it. Another was the proliferation, particularly in the United States around the period of the 1960s and 1970s, of views that were serious alternatives substantially different from the earlier range of policies, so that the utility of policy orientation in solving those problems was less apparent.

What sorts of things might happen next? The events in Eastern Europe suggest one short term, but substantial, item. It is reasonably clear to me that the events in Eastern Europe have revitalized the spirit of mainstream liberalism. My sense has been that there was a fair amount of wheel-spinning among liberal jurisprudence. They had a system and they were working it out. If you were inside the system the problems were sort of interesting, but it was not terribly engaging, because it did not have a political push behind it. The events in Europe, I think, have given mainstream liberalism the kind of energy that it lacked in the past five or ten years. I suspect that that will be, in the sweep of things; a relatively short-term phenomenon, but it will be a substantial part of jurisprudence over the next decade. I am not entirely clear what can be made of that - that is, what mainstream liberals will be able to do with the events in Eastern Europe except to give them self-confidence about their enterprise.

I want to identify two other areas of post-critical jurisprudence that seem to me more interesting; feminist and post-modern jurisprudence. Feminist jurisprudence takes a variety of forms. For example, the first form of feminist jurisprudence was to use the existing forms of legal thought to address problems that were seen by theorists to be distinctively women's problems. In the course of that, there developed a women's perspective or women's form of legal thinking, supported by the work of Carol Gilligan and others. For our purposes here, I want to characterize that as a challenge to the objectivism 
that pervaded mainstream jurisprudence: a challenge that occurred both in style - the legacy of conscious raising discussions, a personalization of the discourse of jurisprudence - and in substance, in its challenge to objectivism. The difficulty with the challenge to objectivism is that there is a tension, not to my mind yet resolved, in the literature of feminist jurisprudence between a non-objectivist's view of law and the inherited notion of the rule of law that is our (male, according to feminist jurisprudence) cultural legacy. In that sense too, there is a confrontation between the feminist jurisprudence and the reconstruction of liberalism which is committed to some form of the rule of law idea.

Before turning to post-modernism I would like to mention one additional aspect of feminist jurisprudence which recently has attracted a fair amount of attention. This is the claim within some forms of feminist thought that there is a 'women's perspective'. This makes a claim of essentialism about the gender-aspect of viewing the world, and raises a number of problems. For example, it unifies all living in ways that seem accurate, to the extent that it treats these perspectives as essentially grounded in gender. But it is puzzling how there could be discourse across gender lines if there is some essential perspective that arises from gender that women' have, and presumably a different one, that men have. It is hard to figure out what the exchange between them could possibly be.
The second post-critical movement, labelled post-modernism, is connected to the prior discussion in that it questions the distinction between objectivism and subjectivism that is implicit in the way $I$ have framed the feminist challenge to the mainstream. At most, for the post-modernist; the distinction between objectivism and subjectivism is culturally constructed. The bite of the claim of the post-modernists is that our contemporary culture cannot support that distinction anymore. To the extent that discussions are cast in terms of objectivity and subjectivity they are trying to live off of a legacy that has essentially been dissipated and so cannot really generate anything anymore. For myself, I find the post-modernist's position extremely interesting but a little puzzling. Puzzling for me because the people who offer it, at least in the United States, seem to be located on the political left and yet they cannot have any reason for being on the left given their challenge to the entire terms of the discussion. At some level, the project for post-modernists is to figure out if there is any connection between these apparent political positions and the jurisprudential position to which they are committed.

Mark V. Tushnet, Professor of Law, Georgetown University Law Centre, Washington, D.C.

Professor Tushnet's McDonald Lecture, "The Possibilities of Interpretive Liberalism" will appear in the Centret forthooming annual supplement to the Alberta Law Review, Constitutional Studies / Études contitutionnelles [ed.]

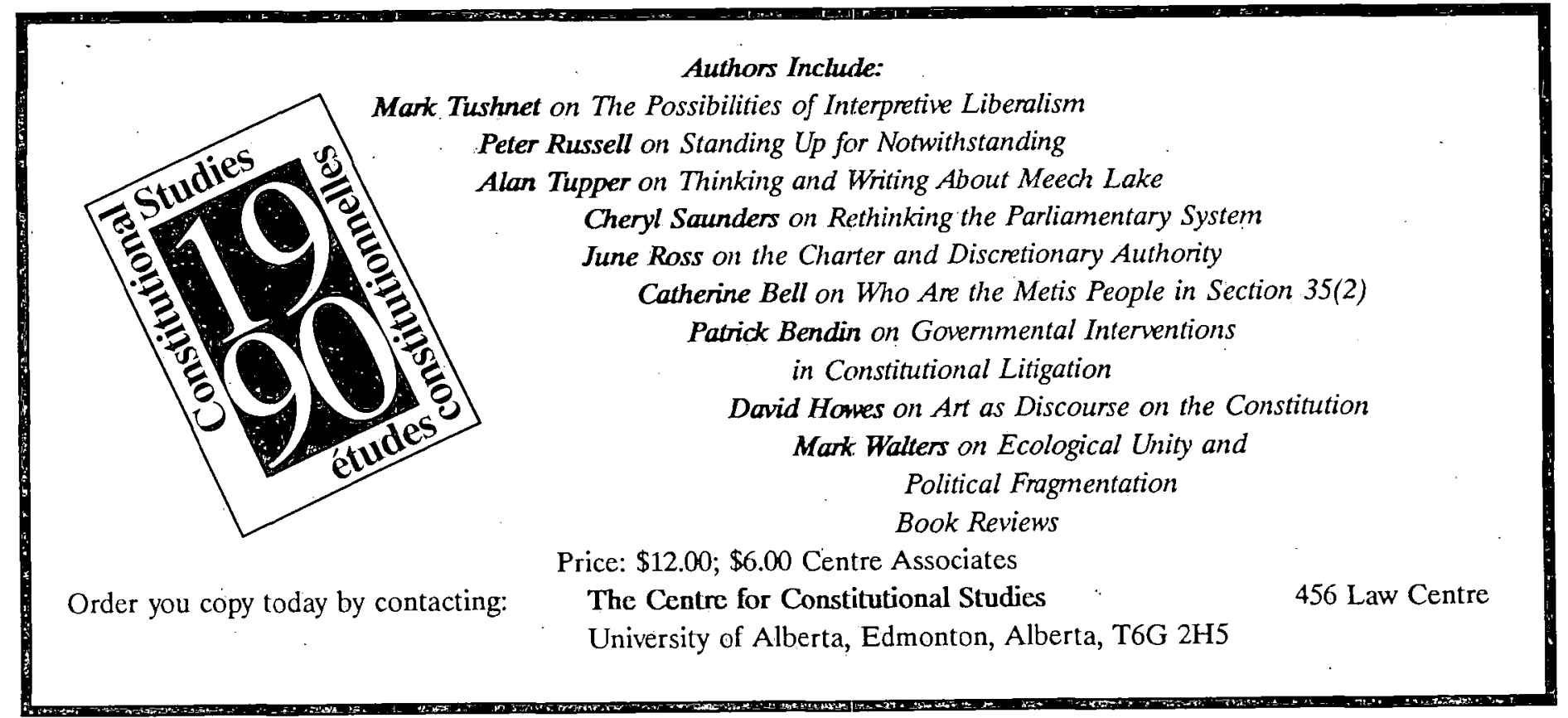

